\title{
ORIGINAL
}

\section{EVOLUCIÓN DE LA ENFERMEDAD MENINGOCÓCICA EN LA POBLACIÓN INFANTIL DE LA COMUNIDAD VALENCIANA (1996-2000). EFECTIVIDAD DE LA VACUNACIÓN ANTIMENINGOCÓCICA A+B}

Mercedes Goicoechea Sáez (1), Ana Mª Fullana Montoro (1), Pilar Momparler Carrasco (1), M. ${ }^{\mathrm{a}}$ Jesús Redondo Gallego (1), Juan Brines Solanes (2) y Francisco J. Bueno Cañigral (3)

(1) Servicio de Salud Infantil y de la Mujer. Dirección General para la Salud Pública. Consellería de Sanidad de la Comunidad Valenciana.

(2) Servicio de Pediatría. Hospital Clínico Universitario de Valencia.

(3) Concejalía de Sanidad y Consumo. Ayuntamiento de Valencia.

\section{RESUMEN}

Fundamento: El incremento de la enfermedad meningocócica por serogrupo C en la Comunidad Valenciana durante 1996-1997 motivó la realización de una campaña de vacunación antimeningocócica $\mathrm{A}+\mathrm{C}$ en la población de 18 meses a 19 años de edad (entre septiembre y diciembre de 1997). El objetivo de este estudio es analizar el impacto de la campaña en cuanto a la epidemiología, clínica evolución de la enfermedad meningocócica y estado de vacunación de la población infantil con el fin de valorar la efectividad vacunal.

Métodos: Los datos se obtuvieron de las historias clínicas de los niños menores de 15 años, que presentaron síntomas y signos clínicos sugestivos de enfermedad invasora con aislamiento de Neisseria. meningitidis y/o que cumplían con los criterios de definición de caso establecidos, atendidos en todos los hospitales públicos de la Comunidad Valenciana entre 1996-2000. La evoluci valoró mediante tasas de incidencia. La clínica y su evolución (secuelas y letalidad) mediante la frecuencia y distribución por serogrupo y edad. La efectividad vacunal se calculó según la fórmula de Orestein.

Resultados: Se registró un total de 302 casos de enfermedad invasora por $N$. meningitidis. La tasa de incidencia por serogrupo C en niños menores de 15 años disminuyó tras la campaña de vacunación desde $5,82 / 10^{5}$ habitantes en 1997 a $1,68 / 10^{5}$ habitantes en 1998. Tres años después de la campaña se ha vuelto a tasas similares a la época prevacunal, con un aumento por serogrupo B en los 2 últimos años. El $61 \%$ de las secuelas se da en menores de 5 años. La letalidad fue más elevada para el serogrupo C. La efectividad vacunal al tercer año tras la campaña ha sido del $83,7 \%$ para el grupo de 5-14 años y del 69,1\% para el grupo de 19 meses-4 años.

Conclusión: La vacuna polisacarídica se mostró efectiva para interrumpir el brote. La disminución de la incidencia del serogrupo C es atribuible a la efectividad vacunal obtenida.

Palabras claves: Neisseria meningitidis. Meningitis. Infancia. Incidencia. Vacunas bacterianas. Vacuna antimeningocócica $\mathrm{A}+\mathrm{C}$ Efectividad.

Correspondencia:

Mercedes Goicoechea Sáez.

Pl Poeta Eduardo Marquina ${ }^{\circ} 4$ pta $20^{\mathrm{a}}$

46014 Valencia

Correo electrónico: mergoico@terra.es

\section{ABSTRACT}

Evolution of Meningococcal Disease among the Infantile Population in the Autonomous Community of Valencia

(1996-200). Effectivity of A+C Meningococcal Vaccination

Bacground: The increase in meningococcal disease caused by serogroup $\mathrm{C}$ in the Autonomous Community of Valencia during the 1996-1997 period gave rise to an A+C meningococcal vaccination campaign having been conducted targeting the population ranging from 18 months to 19 years of age. The purpose of this study is that of analyzing the impact of this campaign regarding the epidemiology, clinical aspects and evolution of meningococcal disease and the vaccination status of the youth population for the purpose of evaluating the efficacy of this vaccination.

Methods: The data was taken from the clinical records of the children under 15 years of age who showed clinical signs an symptoms suggesting an invasive disease with isolation of Neisseria meningitidis and/or which meet the established case definition criteria which had been treated at all of the public hospital in the Autonomous Community of Valencia within the 1996-2000 period. The trend of incidence was ever trind of clinical aspects and their progress (sequelae and lethality) by frequency and distribution by serogroup and age.
cacy was calculated using the Orestein equation.

Results: A total of 302 cases of invasive disease caused by N. Meningitidis were recorded. The rate of incidence by serogroup $\mathrm{C}$ in children under age 15 dropped following the vaccination campaign from $5.82 / 10^{5}$ habitants in 1997 to $1.68 / 10^{5}$ habitants in 1998 . Rates similar to those prior to the time prior to the vaccination recorded three years subsequent to the campaign, showing an increase in the three years subsequent to the campaign, showing an increase in the
disease caused by serogroup B over the last 2 years. Sixty-one perdisease caused by serogroup B over the last 2 years. Sixty-one per-
cent of the sequelae were among children under 5 years of age. Lethality was higher for serogroup C. Vaccination efficacy three years subsequent to the campaign was $83.7 \%$ for the 5-14 age range and $69.1 \%$ for the 19 month- 4 year age range.

Conclusion: The polysaccharide vaccine was shown to be effective for halting the outbreak. The drop in the incidence of serogroup $\mathrm{C}$ can be attributed to the vaccination efficacy achieved.

Key words: Neisseria meningitidis. Meningitis. Infant. Incidence. Bacterial vaccines. Effectiveness. $\mathrm{A}+\mathrm{C}$ meningococcal vaccine. 


\section{INTRODUCCIÓN}

Neisseria meningitidis es una de las causas más frecuentes de meningitis bacteriana y la responsable de importantes epidemias en todo el mundo. Coloniza habitualmente la rinofaringe de los niños y jóvenes. Se calcula que entre el 5-15\% de los adolescentes y el $1 \%$ de los adultos son portadores asintomáticos de $N$. meningitidis. Por el contrario, no es frecuente que los lactantes presenten colonización por este microorganismo ${ }^{1}$.

La incidencia de la enfermedad meningocócica varía según la edad, siendo los jóvenes los más afectados, especialmente los menores de 5 años. En situaciones epidémicas también los niños y adolescentes son los grupos más afectados. Generalmente la enfermedad invasora por este microorganismos presenta un patrón estacional con máxima incidencia en invierno y primavera ${ }^{1-2}$. La incidencia es mayor cuando existen factores predisponentes, es decir, la infección puede tener carácter oportunista ${ }^{3}$.

La infección ocasiona típicamente procesos infecciosos de carácter agudo (meningitis purulenta, sepsis fulminante). La aparición de casos esporádicos o agrupación de casos (cluster) origina una gran angustia entre la población, ya que a pesar de un diagnóstico precoz y de un tratamiento adecuado, muchos de estos procesos tienen desenlaces no deseados, produciéndose secuelas graves e incluso la muerte ${ }^{4}$.

El patrón epidemiológico de la enfermedad meningocócica está asociado estrechamente al serogrupo causante de la infección. Las cepas pertenecientes a los serogrupos A, B y C son las responsables del $80 \%-90 \%$ de los casos de enfermedad meningocócica en el mundo, los serogrupos $\mathrm{Y}$ y $\mathrm{W}_{135}$ son los causantes del 10\%-20\% restante. El serogrupo A es responsable habitualmente de brotes epidémicos en África central y otros países en vía de desarrollo. El serogrupo B predomina en países desarrollados dando lugar a casos esporádicos. En la última década la situación epidemiológica empieza a cambiar en algunos países industrializados, observándose un notable incremento del serogrupo $\mathrm{C}$, que afecta particularmente a los jóvenes produciendo brotes y ocasionalmente epidemias $^{1,5-6}$.

En España hasta la década de los 90 el serogrupo B ocasionaba la mayor parte de los casos, siendo raro los aislamientos de

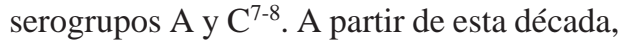
se observó una tendencia creciente de las cepas del serogrupo $\mathrm{C}$, que se fue consolidando en años sucesivos, pasando de un porcentaje de aislamientos del serogrupo $\mathrm{C}$ del $28 \%$ en el año 1993 al $59 \%$ en el año $1996^{7,9-}$ ${ }^{11}$ y que llegó al $61 \%$ en $1997^{12}$ y un marcado aumento de la enfermedad, debido sobre todo a la cepa epidémica C:2b:P1.2,5 a partir de la temporada 1995-1996 ${ }^{12-14}$. También se modificó el comportamiento epidemiológico de la enfermedad, con mayor afectación de adolescentes y jóvenes, tendencia a «cluster» e incremento en la letalidad.

En la Comunidad Valenciana no existen datos fidedignos de la incidencia real de la enfermedad invasora por $N$. meningitidis, al no haber sido una enfermedad de declaración obligatoria (EDO) hasta 1997, año en que se adoptan las definiciones de caso de todas las enfermedades sometidas a vigilancia, aunque anteriormente a esta fecha se basaban en criterio de sospecha clínica ${ }^{15}$. En la década de los 90 en la Comunidad Valenciana se observa que, al igual que en el resto de España, la enfermedad meningocócica presenta una endemia en torno a 3 casos por 100.000 habitantes/año con ciclos epidémicos multianuales y un patrón estacional claro, con máxima incidencia en invierno y primavera $^{16}$. Y a partir de 1994 se fue observando un ligero incremento de la incidencia de enfermedad meningocócica, pasando de una tasa de 2,39 casos por 100.000 habitantes en este año, a una tasa de 4,69 en el año 1997 y una tendencia creciente de aislamientos de $N$. meningitidis del serogrupo C que se 
hizo más patente a lo largo de 1997, hasta el extremo de convertirse en el serogrupo más frecuente $(73 \%)$ y el principal causante de la mortalidad por enfermedad meningocócica $(11,3 \%)^{12,16-17}$.

El análisis de la situación clínico-epidemiológica y la disponibilidad de una vacuna polisacarídica para el serogrupo $\mathrm{C}$, efectiva en el control de brotes y epidemias ${ }^{4,18-19}$ hizo que la Consellería de Sanidad de la Generalidad Valenciana ofertara (entre el 29 de septiembre y el 11 de diciembre de 1997) la vacunación gratuita frente a $N$. meningitidis del serogrupo $\mathrm{C}$ a todos los niños y jóvenes entre 18 meses y 19 años de edad, la cual que se llevó a cabo mediante la vacuna antimeningocócica $\mathrm{A}+\mathrm{C}^{20}$. La actual disponibilidad de una vacuna conjugada contra el serogrupo C de $N$. meningitidis (ofertada de manera gratuita a todos los niños/as menores de 7 años en octubre de 2000 y posteriormente incluida en el Calendario de Vacunaciones Sistemáticas de la Comunidad Valenciana, administrándola a los 2, 4 y 6 meses de edad) ${ }^{21}$, incrementa el interés de la cuestión planteada sobre la duración de la inmunidad en los niños inmunizados con vacuna simple de polisacáridos ${ }^{22-24}$, ya que de estos datos se pueden extraer conclusiones en relación con la eficacia clínica de las vacunas y de la conveniencia de la revacunación $^{25-26}$.

Los objetivos del presente estudio clínico y epidemiológico han sido: 1) Conocer las características más notables en cuanto a la incidencia, distribución etaria, presencia de factores predisponentes y/o antecedentes de problemas de salud, presentación clínica y evolución de la enfermedad bacteriana invasora por Neisseria meningitidis en la población de 0 a 14 años de edad de la Comunidad Valenciana durante el periodo de 1996 a 2000. 2) Valorar la efectividad de la vacunación adoptada en la prevención de la enfermedad invasora por meningococo del serogrupo $\mathrm{C}$ en la Comunidad Valenciana, realizada en el último trimestre de 1997.

\section{SUJETOS Y MÉTODOS}

Se diseñó un estudio descriptivo de todos los casos de enfermedad bacteriana invasora por $N$. meningitidis en niños/as de 1 mes a 14 años de edad inclusive, atendidos entre el 1 de enero de 1996 al 31 de diciembre de 2000 en los Servicios de Pediatría de los 18 hospitales públicos (con asistencia pediátrica) de la Comunidad Valenciana.

La información se obtuvo de las historias clínicas (localizadas a través de los registros internos de los Servicios de Pediatría) de los niños que cumplían uno o más de los siguientes criterios de definición de caso:

Cuadro clínico infeccioso compatible con enfermedad bacteriana invasora (meningitis, septicemia, neumonía, pleuritis, celulitis, artritis, osteomielitis, bacteriemia, epiglotitis y peritonitis) y aislamiento de $N$. meningitidis, en un lugar normalmente estéril (sangre, LCR, líquido pleural, derrame articular, aspirado de tejido celular subcutáneo, etc.) ó presencia de cocos gram negativos en líquido cefalorraquídeo (LCR) y/o detección de antígeno $N$. meningitidis en LCR, sangre, orina en un paciente con signos clínico-analíticos característicos de enfermedad invasora y cultivos negativos para cualquier otro germen.

La información se recogió a través de la cumplimentación de un cuestionario diseñado para este estudio. Se registraron en cada uno de los casos los datos relativos a filiación, edad, sexo, manifestaciones clínicas y datos analíticos al ingreso, antecedentes de problemas previos de salud, antibioterapia previa al ingreso, duración de la estancia total en el hospital y especifica en UCI, secuelas, fallecimiento y estado de vacunación frente a $N$. meningitidis serogrupo $\mathrm{C}$ (dato que se recoge de la historia clínica y/o de la cartilla de salud infantil del niño).

Una vez cumplimentado el formulario, los datos se introdujeron en la base de datos 
Figura 1

Casos de enfermedad invasora por $N$. meningitidis según el serogrupo aislado durante los años 1996-2000 en la Comunidad Valenciana. Distribución por meses

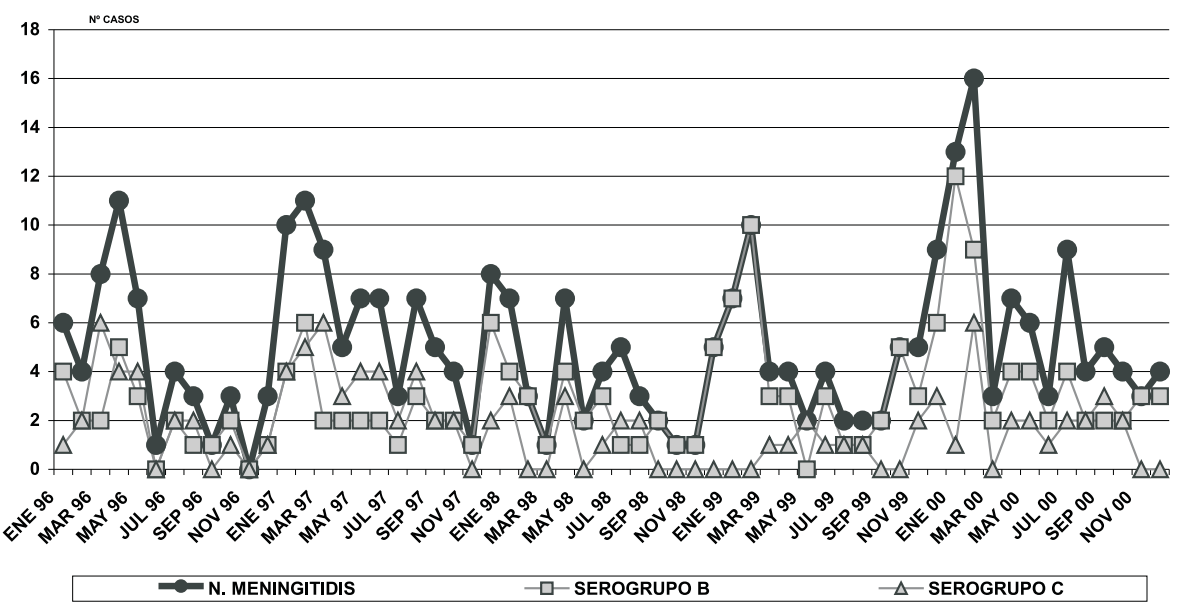

(ACCES), habiéndose procedido previamente a la codificación de algunas variables. Los datos se procesaron en una hoja de cálculo informatizada (EXCEL), para su posterior análisis estadístico y representación gráfica.

Se determinaron: 1) Las tasas de incidencia de la enfermedad por año, que se calcularon a partir de los resultados obtenidos en la población menor de 15 años según el Padrón de 1996 (652.269 personas). 2) La frecuencia y distribución de la infección por edad, sexo, serogrupo, antecedentes de problemas de salud, presentación clínica (número de casos y porcentaje) y la evolución (secuelas y letalidad). 3) La estancia hospitalaria general y la específica en Unidad de Cuidados Intensivos (media y desviación típica). 4) La efectividad vacunal de los años 1998, 1999 y 2000 (calculada según la población vacunada menor de 15 años obtenida del registro numérico elaborado tras la campaña de vacunación ${ }^{20}$ ) mediante la fórmula de Orestein $^{27}$ :

$\mathrm{EV}=[($ Tasa en NO vacunados - Tasa en vacunados)/Tasa en NO vacunados] $\times 100$.

\section{RESULTADOS}

Durante los 5 años del estudio se registró un total de 302 casos de enfermedad invasora por $N$. meningitidis, lo que representa una tasa anual promedio de 9,26 casos por 100.000 habitantes menores de 15 años de edad para el conjunto del periodo estudiado $(7,81 ; 11,80$; 6,$28 ; 8,58$ y 11,80 para $1996,1997,1998$, 1999 y 2000 respectivamente). La infección presenta un patrón estacional con máxima incidencia en invierno y primavera (figura 1).

La distribución por sexo fue de 152 casos en niños $(50,3 \%)$ y 150 casos en niñas $(49,7 \%)$, siendo la razón por sexos de 1,01 . Se identificó el serogrupo causal en el 94,4 $\%$ de los casos. El serogrupo más frecuentemente aislado en los 5 años estudiados fue el serogrupo B (177 casos) seguido del serogrupo C (105 casos). Se observa un fuerte descenso de la incidencia del serogrupo $\mathrm{C}$ en los años 1998 y 1999 y un aumento de éste en el $2000 \mathrm{y}$, un llamativo aumento del serogrupo B en los años 1999 y 2000 (figura 2).

La distribución por serogrupo aislado según la edad queda recogido en la figura 3. 
Figura 2

Casos de enfermedad invasora por $N$. meningitidis durante los años 1996-2000 en la Comunidad Valenciana. Distribución según el serogrupo aislado (número de casos y porcentaje)

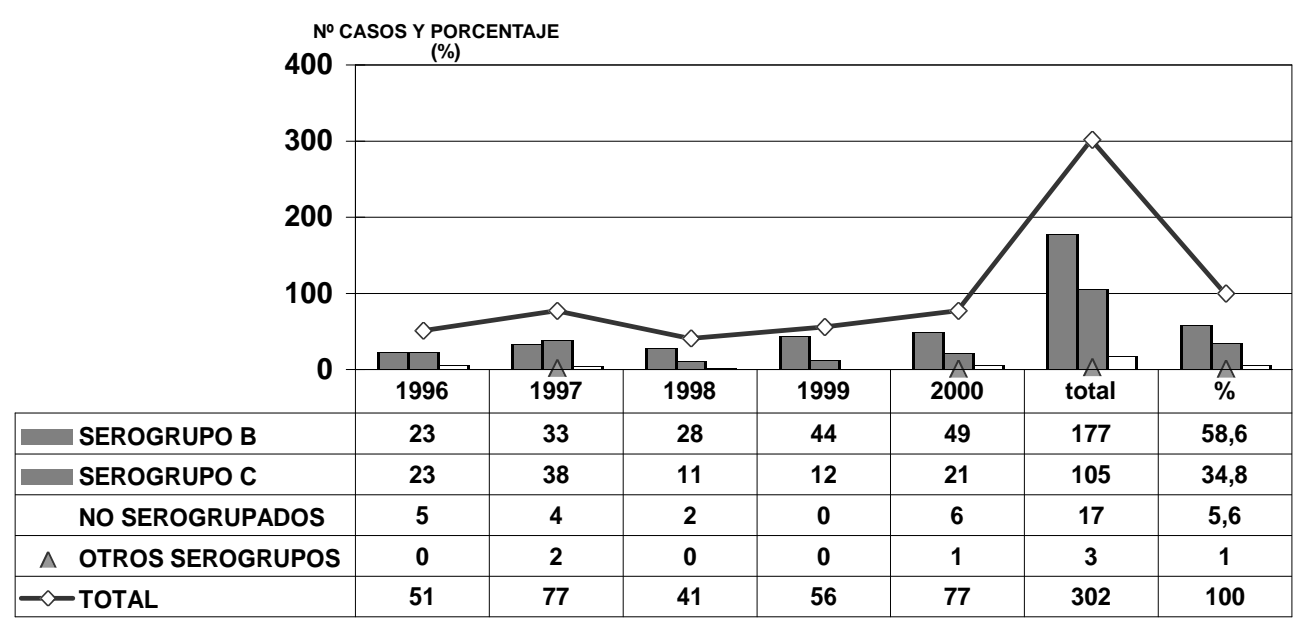

$\square$ SEROGRUPO B $\square$ SEROGRUPO C $\square$ NO SEROGRUPADOS $\triangle$ OTROS SEROGRUPOS $\sim \sim$ TOTAL

Figura 3

Casos de enfermedad invasora por $N$. meningitidis durante los años 1996-2000 en la Comunidad Valenciana. Distribución de serogrupos según la edad (número de casos y porcentaje)

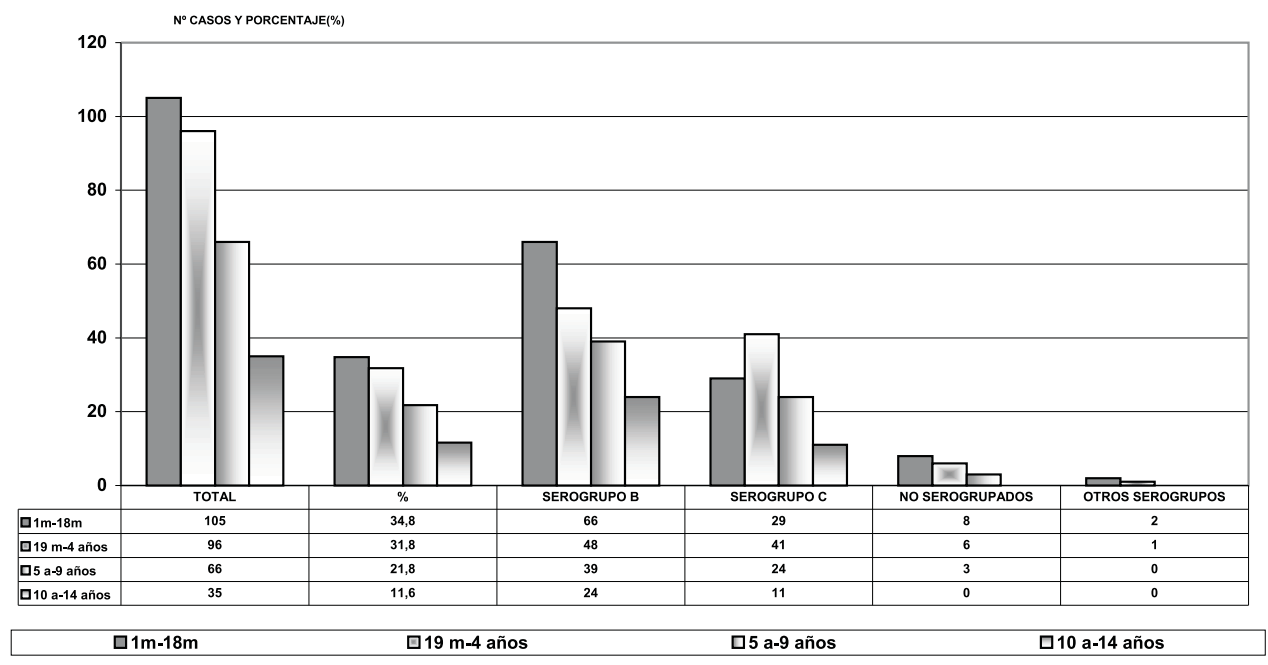


Tabla 1

Número de casos y tasa de incidencia de enfermedad invasora por $N$. meningitidis serogrupo C

\begin{tabular}{|c|c|c|c|c|c|c|c|c|c|c|}
\hline \multirow{2}{*}{ Edad } & \multirow{2}{*}{\multicolumn{2}{|c|}{$\begin{array}{c}1996 \\
n^{\circ} \text { casos T. incd. }\end{array}$}} & \multicolumn{2}{|c|}{1997} & \multicolumn{2}{|c|}{1998} & \multicolumn{2}{|c|}{1999} & \multicolumn{2}{|c|}{2000} \\
\hline & & & $n^{o} \mathrm{cc}$ & T. incd. & $n^{o} \mathrm{cc}$ & T. incd. & $n^{o} c c$ & T. incd. & $n^{o}$ casos & T. incd. \\
\hline 1 mes- 18 meses & 6 & 11,22 & 15 & 28,06 & 4 & 7,48 & 3 & 5,61 & 1 & 1,87 \\
\hline $19 \mathrm{~m}-4$ años & 8 & 5,86 & 10 & 7,33 & 5 & 3,66 & 7 & 5,13 & 11 & 8,07 \\
\hline 5 a-9 años & 6 & 2,81 & 9 & 4,22 & 2 & 0,93 & 1 & 0,46 & 6 & 2,81 \\
\hline $10 \mathrm{a}-14$ años & 3 & 1,20 & 4 & 1,60 & 0 & 0,00 & 1 & 0,40 & 3 & 1,20 \\
\hline 1 mes- 14 años & 23 & 3,52 & 38 & 5,82 & 11 & 1,68 & 12 & 1,83 & 21 & 3,21 \\
\hline
\end{tabular}

Población: Fuente. Padrón 1996.

El mayor número de casos se da antes de los 5 años de edad (66,6\% del total de los casos), especialmente antes de los 18 meses $(34,8 \%$ del total de los casos). El número de casos disminuye a medida que aumenta la edad. La enfermedad invasora por $N$. meningitidis del serogrupo $\mathrm{C}$ aparece en el $67 \%$ de los casos antes de los 5 años de edad y en el $39 \%$ de los casos en el grupo de 19 meses a 4 años.

En la tabla 1 se recoge el número de casos y las tasas de incidencia por grupos etarios de la enfermedad invasora por $N$. meningitidis del serogrupo C. Se observa una reducción de la enfermedad meningocócica por serogrupo $\mathrm{C}$ con relación a la temporada prevacunal $(64 \%, 61 \%$ y $31 \%$ en el conjunto de niños/as menores de 15 años de edad durante los años 1998, 1999 y 2000 respectivamente) y un progresivo aumento de la tasa de incidencia de enfermedad invasora por $N$. meningitidis serogrupo $\mathrm{C}$ desde el año 1998 entre los niños/as no vacunados y con edades comprendidas entre los 19 meses y los 14 años de edad inclusive.

Todos los casos registrados de enfermedad invasora por $N$. meningitidis del serogrupo C, en los dos años anteriores a la campaña vacunal, se dan en niños/as no vacunados lo que representa una tasa de incidencia de 2,83/ 100.000 y $3,84 / 100.000$ niños/as con edades comprendidas entre los 19 meses-14 años de edad para los años 1996 y 1997 respectivamente.
En los dos años siguientes a la vacunación se observó un descenso de los casos de enfermedad meningocócica debido al serogrupo $\mathrm{C}$ en niños/as vacunados, con una tasa de incidencia de 0,54/100.000 y $0,36 /$ 100.000en niños/as en edades comprendidas entre 19 meses-14 años y un aumento de incidencia en los no vacunados 7,74/100. 000 y 13,55/100.000 entre los niños/as de este mismo grupo de edad para los años 1998 y 1999 respectivamente. En el año 2000 se produjo un incremento de casos debidos al serogrupo $\mathrm{C}$, reflejando una tasa de incidencia de 1,46/100.000 niños/as vacunados de edades comprendidas entre 19 meses-14 años de edad y de 19,36/100.000 niños/as no vacunados del mismo grupo de edad.

El serogrupo B mantiene prácticamente igual la incidencia durante el año posterior a la campaña de inmunización (28 casos en 1998), experimentando un aumento progresivo del número de casos y por lo tanto de su tasa de incidencia en los años 1999 y 2000 (44 y 49 casos respectivamente), lo que representa un aumento del $58 \%$ en el año 1999 y del $75 \%$ en el año 2000 con respecto a los 3 años anteriores del estudio, especialmente en menores de 18 meses.

Se documentó un total de 25 condicionantes médicos previos y/o antecedentes de problemas de salud (prematuridad 24\%, cardiopatías congénitas $12 \%$, infecciones respiratorias superiores de repetición $12 \%$, Síndrome de Down $8 \%$, neoplasias $8 \%$, inmunode- 
ficiencias primarias $8 \%$, niños/as sin ninguna vacunación del calendario vacunal $12 \%$, malnutrición $8 \%$, varicela 10 días antes $8 \%$ ) presentes en 23 niños, lo que representa un $7,6 \%$ de los niños con enfermedad invasora por este microorganismo: Con enfermedad invasora por $N$. meningitidis del serogrupo B 11 casos, por serogrupo $\mathrm{C} 9$ casos, por serogrupo A 1 caso y por no serogrupado 2 casos. Un $78 \%$ eran menores de 5 años.

La meningitis fue la presentación clínica más frecuente en el total de los 5 años del estudio con el $61 \%$ del total de casos (en el $15 \%$ sólo como meningitis, en el $46 \%$ con un cuadro conjunto de meningitis y sepsis/bacteriemia) seguida de la sepsis/bacteriemia con el 37\%, infección osteoarticular 1\%, neumonía $0,7 \%$ y celulitis $0,3 \%$ (figura 4 ). La infección osteoarticular se manifestó en un total de 8 casos, 3 de ellos como cuadro principal y en 5 ocasiones más como cuadro secundario: en 4 casos conjuntamente con un cuadro de meningitis con sepsis/bacteriemia por meningococo B y en 1 caso acompañando a un cuadro de meningitis por meningococo $\mathrm{C}$.
En el 96\% de los casos (290) se aisló meningococo, en el 3\% (8) el diagnóstico se realizó exclusivamente por detección de antígeno y en el $1 \%$ por identificación de cocos gram negativos (4 casos con manifestaciones clínicas de meningitis bacteriana y sin identificación de germen en ningún cultivo). Un $21 \%$ de los niños habían tomado una o más dosis de algún antibiótico previamente al ingreso.

La media de días de hospitalización de todos los niños con enfermedad invasora por $N$. meningitidis serogrupo B fue de 10,4 (DS 2,9) y para el serogrupo $\mathrm{C}$ fue de 10,7 (DS $2,8)$. Precisaron ingreso en UCI un $57,2 \%$ de todos los hospitalizados con una estancia media para el serogrupo B de 3,5 (DS 2,3) y para el serogrupo $\mathrm{C}$ de 3,6 (DS 2,1). Se observó una disminución, estadísticamente no significativa, de la estancia hospitalaria general y específica en UCI en los años 1998 y 1999 para los ingresados por N. meningitidis serogrupo C (figura 5). La duración de la hospitalización, estancia en UCI y porcentaje de casos que precisaron cuidados intensi-

Figura 4

Manifestación clínica de enfermedad invasora por $N$. meningitidis (número de casos y porcentaje)

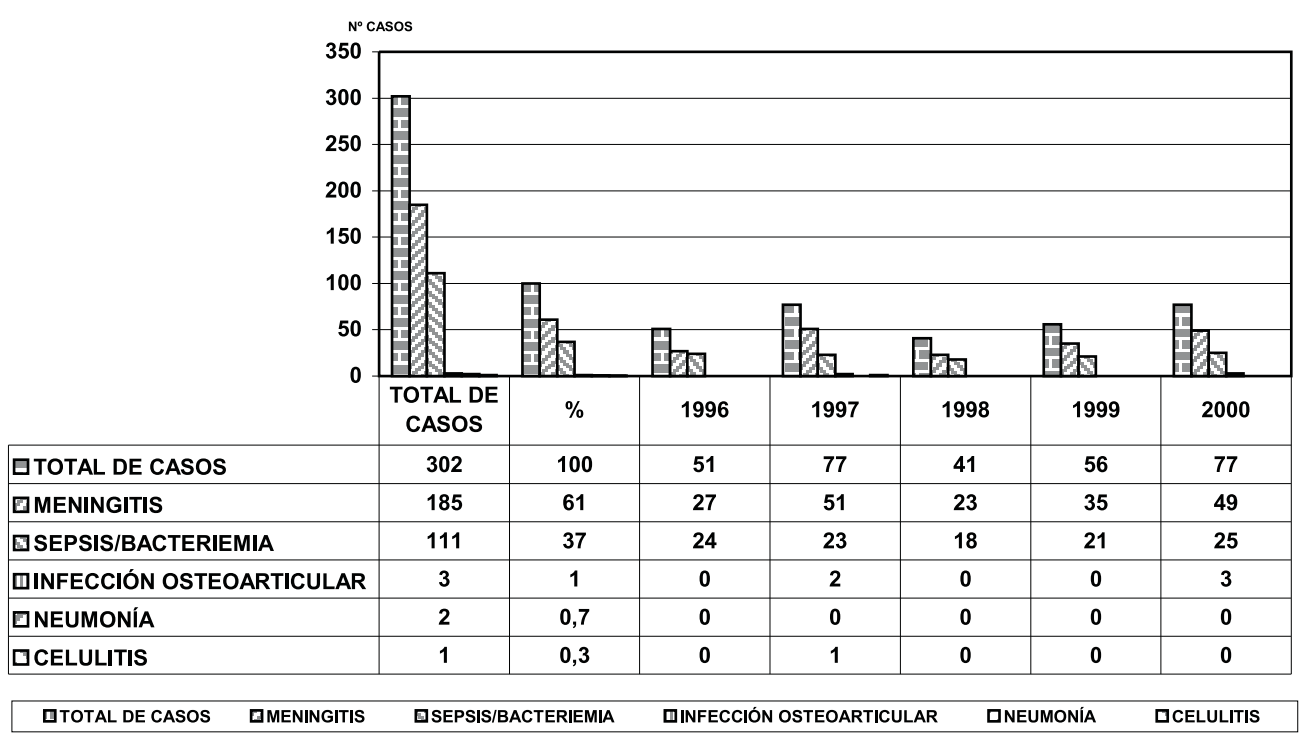


Figura 5

Días de hospitalización (media) y estancia en UCI (media) durante los años 1996-2000

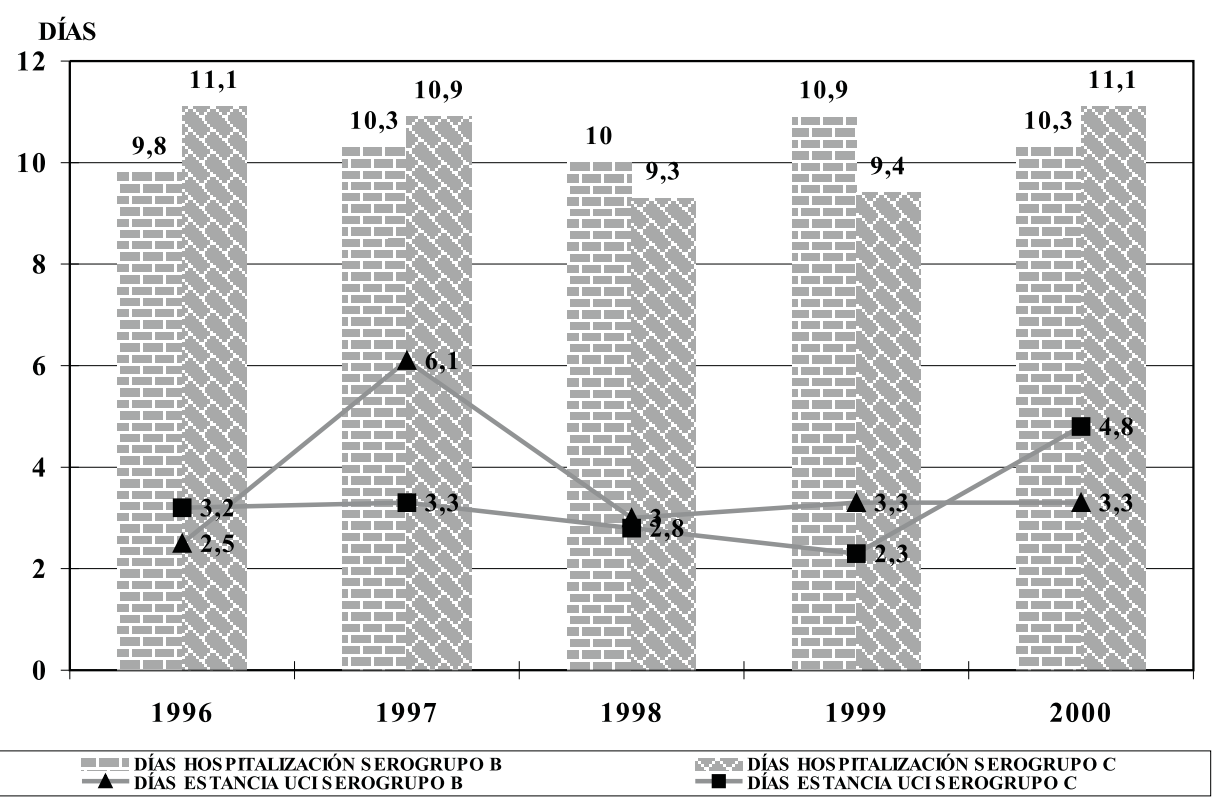

vos según la manifestación clínica queda reflejada en la tabla 2 . No se incluyen en estas valoraciones los niños/as fallecidos.

Evolucionaron a la curación 263 niños ( $87 \%$ de los casos). El número de fallecimientos fue de 16 casos (todos ellos por shock séptico y en 7 pacientes de forma fulminante) lo que representa una letalidad del $5,3 \%$ en el total del periodo estudiado. De ellos 6 casos fueron debidos a $N$. meningitidis del serogrupo B (letalidad del 3,4 \%) y 10 casos por $N$. meningitidis del serogrupo C (letalidad del 9,5\%) (tabla 3). En 3 de los niños/as la enfermedad invasora se daba en pacientes con antecedente médicos de problemas de salud (inmunodeficiencia primaria, síndrome de Down y episodios repetitivos de bronquitis obstructiva aguda y bronquiolitis). Los 3 niños eran menores de 2 años, presentaban al ingreso un cuadro clínico de sepsis/bacteriemia y no estaban vacunados.

Al alta presentaron secuelas 23 niños (7,6\% de los casos), en 4 de ellos se docu- mentó más de una. Un 66\% de las secuelas se produjeron tras enfermedad invasora por meningococo serogrupo B, un $30 \%$ tras enfermedad invasora por meningococo serogrupo $\mathrm{C}$ y $4 \%$ por meningococo no serogrupado. Estas secuelas se han producido en un $(52 \%)$ a expensas de un cuadro clínico de meningitis y en un (48\%) como consecuencia de una sepsis. El $61 \%$ de estas secuelas aparecen en menores de 5 años principalmente en pacientes entre 1 y 18 meses (48\%). Se observó un progresivo aumento de estas en los años 1999 y 2000, debidas fundamentalmente a enfermedad invasora por N. meningitidis del serogrupo B (tabla 4).

En la tabla 5 se relaciona el número de casos y de fallecidos por $N$. meningitidis serogrupo $\mathrm{C}$ en función del estado de vacunación frente al meningococo $\mathrm{A}+\mathrm{C}$. A partir del año 1998, trece niños/as vacunados frente al meningococo $\mathrm{C}$ presentaron enfermedad invasora por este microorganismo (10 niños vacunados con edades comprendidas entre los 18 meses y los 2 años, un niño vacunado con 
Tabla 2

Días de hospitalización y estancia en UCI según la manifestación clínica que presentaron (media y desviación típica) y porcentaje de casos que precisaron UCI

\begin{tabular}{|cccc|}
\hline Manifestación clínica & Días de hospitalización & Días de UCI & ${\text { Ingresados en UCI }(\%)^{* *}}^{* *}$ \\
Maningitis & $10,7 \pm 2,6$ & $3,5 \pm 2,1$ & 56,6 \\
Sepsis/Bacteriemia & $9,9 \pm 3,1$ & $3,5 \pm 2,2$ & 64,0 \\
Neumonía & $16,0 \pm 2,8$ & $10,0 \pm 4,2$ & 100 \\
Otros cuadros & $12,3 \pm 5,0$ & $5,5 \pm 4,8^{*}$ & 50 \\
\hline
\end{tabular}

* Corresponden a infección osteoarticular (2), celulitis (1).

** Denominador: Número total de casos de N. meningitidis de los 5 años de estudio según la manifestación clínica que presentaron.

\section{Tabla 3}

Fallecimientos de enfermedad invasora por $N$. meningitidis en la infancia (número de fallecidos) por año de estudio y letalidad (\%)

\begin{tabular}{|c|c|c|c|c|c|c|c|}
\hline Microorganismo & 1996 & 1997 & 1998 & 1999 & 2000 & $N^{o}$ total & Letalidad $(\%)^{*}$ \\
\hline N. meningitidis serogrupo B & 1 & 2 & & 2 & 1 & 6 & 3,4 \\
\hline N. meningitidis serogrupo C & 4 & 3 & 1 & & 2 & 10 & 9,5 \\
\hline $\mathrm{N}^{\circ}$ total y Letalidad (\%)** & $5(9,8)$ & $5(6,5)$ & $1(2,4)$ & $2(3,6)$ & $3(3,9)$ & 16 & 5,3 \\
\hline
\end{tabular}

* Denominador: Número total de casos de los 5 años de enfermedad invasora por N. meningitidis.

** Denominador: Número total de casos de enfermedad invasora por N. meningitidis de cada año de estudio.

Tabla 4

Número y tipo de secuelas tras enfermedad invasora por $N$. meningitidis de los serogrupos $\mathrm{B}, \mathrm{C}$ y no serogrupado

\begin{tabular}{|lccc|}
\hline Tipo de secuela & N. meningitidis $B$ & N. meningitidis $C$ & N. meningitidis no serogrupado \\
\hline Sordera & 4 & 2 \\
Perdida de visión & 1 & & \\
Trast. de la conducta & 1 & & \\
Alt. TAC & 2 & 2 & 1 \\
Alt. motora & 3 & 1 \\
Lesiones cutáneas & 6 & 2 \\
Amputación miembro inf. & 1 & 1 & \\
Otras* & $\mathbf{1 8}$ (en 15 niños) & $\mathbf{8}$ (en 7 niños) & $\mathbf{1}$ (en 1 niño) \\
Total &
\end{tabular}

* Corresponde a insuficiencia renal crónica (2).

3 años de edad, una niña vacunada con 6 años y un niño vacunado con 10 años ). Hubo un fallecimiento entre los niños vacunados (niña de 5 años vacunada con 2 años). Dos niños de 1 y 5 años respectivamente y no vacunados fallecen en el curso de la enfermedad. 
Tabla 5

Número de casos y de fallecidos de enfermedad invasora por $N$. meningitidis $\mathrm{C}$ en función del estado de vacunación frente a este microorganismo

\begin{tabular}{|ccccccc|}
\hline & \multicolumn{2}{c}{ Vacunados } & \multicolumn{2}{c|}{ No vacunados } & \multicolumn{2}{c|}{ No consta } \\
\hline & $N^{o}$ casos & Fallecidos & $N^{o}$ casos & Fallecidos & $N^{o}$ casos & Fallecidos \\
\hline 1996 & 0 & 0 & 23 & 4 & 0 & 0 \\
1997 & 0 & 0 & 38 & 3 & 0 & 0 \\
1998 & 3 & 0 & 8 & 1 & 0 & 0 \\
1999 & 2 & 0 & 10 & 0 & 0 & 0 \\
$\mathbf{2 0 0 0}$ & 8 & 1 & 11 & 1 & 2 & 0 \\
\hline
\end{tabular}

La efectividad vacunal sobre la morbimortalidad de $N$. meningitidis serogrupo C en la población menor de 15 años se calculó según la fórmula de Orestein. Para este cálculo se ha seguido a la población vacunada durante la campaña. En el primer año tras la campaña de vacunación (1998) se registraron 11 casos de enfermedad meningocócica por serogrupo C ( 3 en vacunados y 4 en no vacunados); la efectividad de la vacuna fue del $86,2 \%$ para la población vacunada de 19 meses-4 años y del 93,5\% para la población vacunada de 5 a 14 años inclusive. En 1999 se registraron 12 casos ( 2 en vacunados y 2 en no vacunados); la efectividad para este año fue del 79,4\% en el grupo de vacunados de 19 meses-4 años y del 93,5\% en el grupo de vacunados de 5 a 14 años inclusive. En el tercer año tras la campaña de vacunación (2000) se registraron 21 casos (8 en vacunados y 4 en no vacunados); la efectividad para este año fue del $69,1 \%$ en el grupo de vacunados de 19 meses-4 años y del 83,7\% en el grupo de vacunados de 5 a 14 años inclusive (tabla 6).

\section{DISCUSIÓN}

El periodo estudiado que comprende el año 1997 de la campaña de vacunación (antimeningocócica $\mathrm{A}+\mathrm{C}$ en la población entre 18 meses y 19 años), así como el año anterior y los tres años posteriores a esta actuación, nos ofrece una referencia objetiva de la evo- lución epidemiológica de la enfermedad bacteriana por $N$. meningitidis en la población infantil de nuestra Comunidad, permitiéndonos obtener, simultáneamente con la valoración de la incidencia, las características clínicas más notables y la efectividad vacunal en los distintos grupos de edad, identificando los que están en mayor riesgo de adquirir la infección y así acentuar y adecuar a ellos/as las intervenciones preventivas.

Se han recogido todos los casos registrados en los Servicios de Pediatría de los hospitales públicos de la Comunidad Valenciana. Podemos suponer que los casos de pacientes con enfermedad invasora por este microorganismo no incluidos en el estudio por haber recibido asistencia extrahospitalaria o por ingreso en hospitales privados deben de ser muy pocos, basándonos en que el Sistema Nacional de Salud ofrece una asistencia de calidad, universal, pública y sin coste para el paciente; en la gravedad de estos procesos; en la obligatoriedad de la declaración de enfermedad de los casos por $N$. meningitidis y en el escaso número de camas pediátricas privadas, especialmente de cuidados intensivos.

La evolución de la incidencia de enfermedad invasora por $N$. meningitidis ha variado a lo largo de los 5 años del estudio. La máxima incidencia (tasa de 11,80) se produjo en el año 1997. En el primer año tras la campa- 
EVOLUCIÓN DE LA ENFERMEDAD MENGOCÓCICA EN LA POBLACIÓN INFANTIL DE LA COMUNIDAD VALENCIANA...

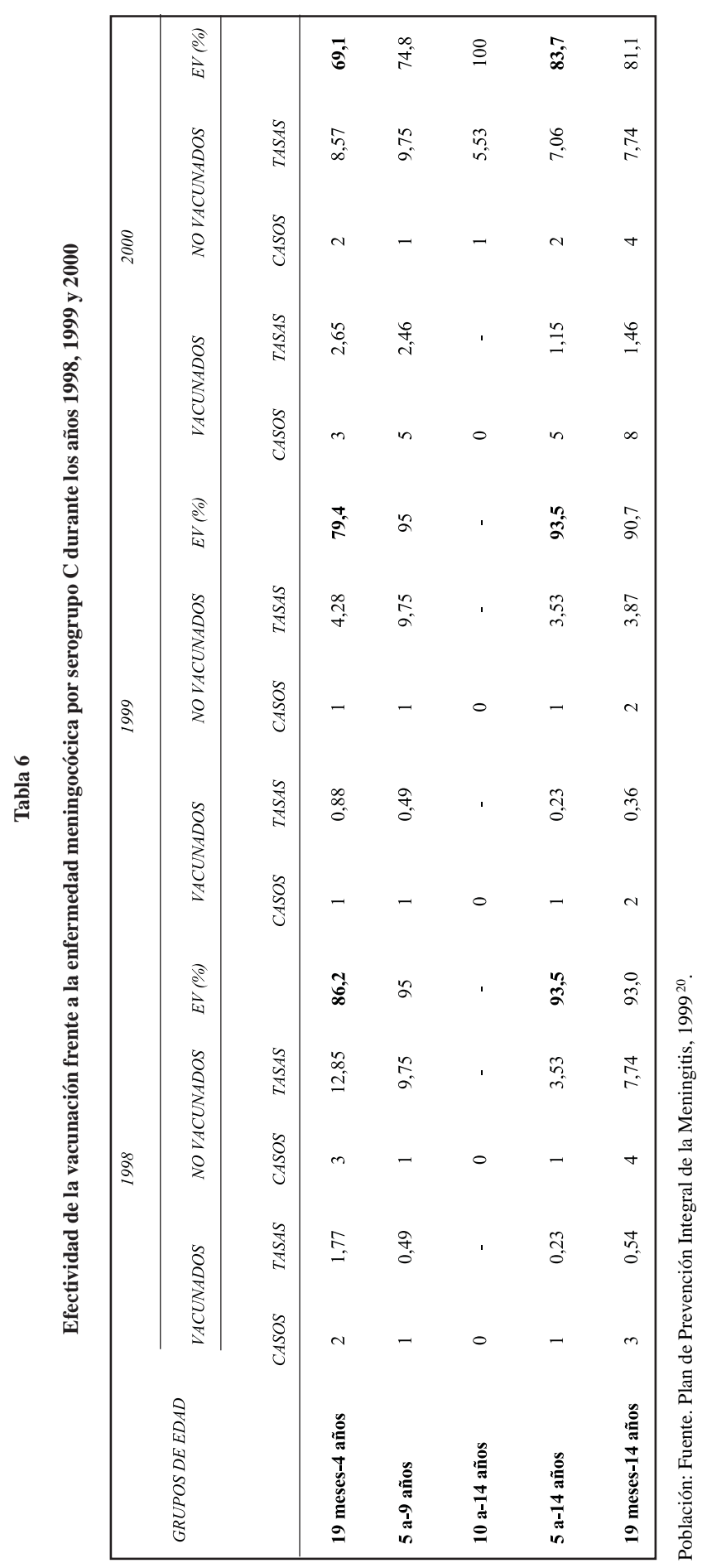

Rev Esp Salud Pública 2003, Vol. 77, N. ${ }^{\circ} 1$ 
ña de vacunación (1998) disminuyó drásticamente (tasa de 6,28), para posteriormente ir aumentando hasta alcanzar un nivel similar al del inicio del periodo de estudio ${ }^{28}$.

Se identificó el serogrupo causal en más del $94,4 \%$ de los niños hospitalizados, lo que es bastante superior a lo descrito en otros trabajos $^{12,29-30}$. En el total de los años del estudio, el serogrupo identificado con mayor frecuencia fue el serogrupo B seguido del serogrupo C, esta situación ha sido observada también por otros autores en España ${ }^{28,31-32}$. El aislamiento de otros serogrupos de $N$. meningitidis ha sido infrecuente, lo que concuerda con otros estudios ${ }^{9,12-13,23-24}$.

La enfermedad invasora bacteriana por $N$. meningitidis puede darse a cualquier edad, sin embargo las mayores tasa de ataque se dan en menores de 5 años, especialmente en los primeros 18 meses de vida. El serogrupo $B$ afecta principalmente a niños menores de 2 años de edad. La mayor tasa de incidencia de enfermedad meningocócica por serogrupo $\mathrm{C}$ se produce principalmente en el grupo etario de 19 meses a 4 años de edad, como se repite en nuestro estudio y en otros ${ }^{9,12,24,33-36}$.

La epidemiología de la enfermedad invasora bacteriana en la infancia se ve fuertemente influida por la administración de vacunas eficaces en la población. La evolución de la incidencia ha sido distinta según el serogrupo. En los años del estudio hemos encontrado en la Comunidad Valenciana un predominio del serogrupo $\mathrm{C}$ sobre el $\mathrm{B}$ en el periodo anterior a la campaña vacunal. $\mathrm{La}$ campaña de vacunación frente al meningococo A+C en 1997 produjo un llamativo descenso de casos de enfermedad invasora por $N$. meningitidis del serogrupo $\mathrm{C}$, pasando de una tasa de 5,82 en 1997 a una tasa de 1,68 en 1998 y manteniendo esta tasa de incidencia a lo largo de 1999 como se refleja también en otros trabajos ${ }^{28,37-38}$. En el año 2000, transcurridos 3 años desde la citada vacunación, vuelve a aumentar la incidencia hasta alcanzar casi el mismo nivel de la etapa pre- vacunal, siendo el grupo de edad de 19 meses a 4 años el principal responsable del aumento observado $^{31}$. El aumento de la incidencia de este grupo de edad puede deberse a lo susceptibles que quedaron tras la campaña de vacunación: los nacidos después de 1997; el creciente número de niños no vacunados por no haber alcanzado la edad de 18 meses en el momento de la campaña de 1997 $\mathrm{y}$; los vacunados que tenían entre 18 meses y 4 años durante la campaña de vacunación, edad en la que disminuye tanto la eficacia de la vacuna polisacarídica que se utilizó contra el meningococo $C^{23,26,39-40}$ como la duración de la inmunidad de esta vacuna a partir del tercer año, hecho observado en este estudio y que concuerda con los resultados de otros trabajos $24,38,41-42$.

Sin embargo la incidencia de la enfermedad invasora por $N$. meningitidis del serogrupo B, no afectado por la vacunación, no mostró cambios significativos durante los tres primeros años del estudio, incrementándose considerablemente en 1999 (tasa de $6,7)$ y 2000 (tasa de 7,5) es decir, un aumento del $58 \%$ y del $76 \%$ respectivamente con relación a los 3 años anteriores (tasa promedio 4,3). Este hecho se aprecia también en otros países donde se administran rutinariamente vacunas eficaces contra el meningococo $\mathrm{C}$ así, en Inglaterra y Gales el mismo año de la campaña se observó un incremento de la incidencia de los serogrupos B y W ${ }_{135}{ }^{43}$. Situaciones similares se han producido en otras Comunidades Autónomas ${ }^{28,30-32}$. En Cantabria $^{30}$, tras la campaña de vacunación de 1997, se ha asistido a un incremento progresivo del serogrupo B con una incidencia en el año 2000 cinco veces superior al C.

A la vista del aumento del serogrupo B en los dos últimos años del estudio nos planteamos la posibilidad, ya apuntada por otros autores $^{44}$, de que se hubiese producido un vacío generado por la intervención («nicho ecológico») que podría estar siendo ocupado por el serogrupo B. Pero según datos procedentes del Servicio de Epidemiología de la 
Dirección General para la Salud Pública (sistema de vigilancia epidemiológica de enfermedades de declaración obligatoria) en la temporada 2001 hemos asistido a un drástico descenso de la enfermedad meningocócica, hecho observado también en el resto de España $^{45}$. Durante este año el número de casos por serogrupo $\mathrm{C}$ se ha reducido en un $67 \%$, mientras que el serogrupo B se ha reducido en un $41 \%$ con respecto al año anterior, cifras que se mantienen durante el año 2002, lo que nos hace pensar que el aumento de casos que hemos observado del meningococo B en los años 1999 y 2000 se debió a una característica onda epidémica.

Al igual que en otros estudios, también se ha relacionado la mayor susceptibilidad a la infección por $N$. meningitidis en niños con otros antecedentes médicos de problemas de salud, fundamentalmente déficits inmunitarios, enfermedades crónicas de base, procesos infecciosos recientes, prematuridad, malnutrición y vida precaria con hacinamiento, como sucedió en el 7,6\% de los pacientes con enfermedad invasora por este microorganismo. El $72 \%$ de los casos se presentaron en menores de 5 años, lo que concuerda con otros trabajos ${ }^{2}$.

La presentación clínica más frecuente fue la meningitis (60\% de los casos) seguida de la sepsis (37\% de los casos). Este orden en la presentación se mantuvo durante todos los años del estudio, con porcentajes del $52 \%$ al $60 \%$ para la meningitis y del $35 \%$ al $48 \%$ para la sepsis. El estudio del Área de Vigilancia Epidemiológica de España ${ }^{12}$ también constató la meningitis como la presentación clínica más frecuente $(51 \%)$ seguido de la sepsis (42\%), si bien en 1997 el orden fue inverso con el $44 \%$ y el $50 \%$ respectivamente. En Galicia la meningitis fue la presentación clínica más común de enfermedad meningocócica en los años anteriores a la campaña de vacunación ${ }^{11,46}$.

En el periodo prevacunal (1996 y 1997) los serogrupos B y C no difieren en su pre- sentación, predominó la forma clínica de meningitis para ambos serogrupos. A partir del año 1998 (periodo postvacunal) el serogrupo B sigue presentándose con mayor frecuencia como meningitis $(61 \%, 70 \%$ y $69 \%$ en 1998,1999 y 2000 respectivamente) que como sepsis $(39 \%, 30 \%$ y $31 \%$ en este mismo periodo), mientras que el serogrupo $\mathrm{C}$ invierte su forma de presentación clínica presentándose con mayor frecuencia como sepsis (en el $55 \%, 58 \%$ y $57 \%$ de los casos de los años 1998, 1999 y 2000) y como meningitis (en el 45\%, $42 \%$ y $38 \%$ en este mismo periodo $)^{28}$.

Los 11 casos de enfermedad invasora por meningococo $\mathrm{C}$ del año 1998 y los 12 casos del año 1999 precisaron una menor estancia hospitalaria e ingreso en UCI que los aparecidos los años anteriores a la campaña de vacunación, aunque sin significación estadística de la diferencia y sin que la misma tuviera relación con la edad, el sexo o el estado de vacunación de los niños; hecho difícil de contrastar con otros autores debido al escaso número de artículos publicados al respecto.

Un 7,6\% del total de los niños/as presentaban secuelas al alta. A expensas de un cuadro clínico de meningitis ( $52 \%$ de los casos) las secuelas neurológicas registradas consistieron, fundamentalmente, en sorderas neurosensoriales, trastornos motores y de la coordinación y retraso mental. Las formas septicémicas ( $48 \%$ de los casos), se tradujeron en fenómenos de vasculitis y consistieron en necrosis cutáneas, subcutáneas y óseas que excepcionalmente pueden llevar a la pérdida de extremidades ${ }^{17,47}$. El $61 \%$ de las secuelas documentadas se dan en menores de 5 años, especialmente en menores de 2 años (48\%), lo que coincide con otros estudios. Se observó un progresivo aumento de secuelas en los años 1999 y 2000, debido fundamentalmente a enfermedad invasora por N. meningitidis serogrupo B (5 y 7 secuelas respectivamente) hecho atribuible al aumento de incidencia de este serogrupo 
en los dos últimos años, dado que el número de secuelas en relación con el número de casos presenta una proporción similar.

Se ha observado una letalidad del $5,3 \%$ en el total del periodo del estudio, destacándose la provocada por el serogrupo C como la más elevada $9,5 \%$. El 94\% de los casos de fallecimiento se produjo en niños menores de 5 años, principalmente en menores de 18 meses $(56 \%)$, cifra similar a la de otros estu$\operatorname{dios}^{31}$ y donde el 7,6\% de la letalidad en este grupo etario fue debida al serogrupo $\mathrm{B}$ y el 13,8\% al serogrupo C. Así mismo, los casos que cursaban con sepsis, presentaron una mayor letalidad que los que se presentaban con meningitis $(9,6 \%$ frente al $3,5 \%)$ situación similar a lo descrito en otros traba$\operatorname{jos}^{2,12}$.

En el periodo prevacunal (1996-1997) la letalidad de la enfermedad meningocócica en general fue del $7,8 \%$, lo que concuerda con otros autores ${ }^{12,31,48-49}$. Al igual que en otros estudios, el serogrupo $\mathrm{C}$ presenta una mayor letalidad $(11,5 \%)$ que el serogrupo B $(5,4 \%)^{11-12,31,48-49}$.

A partir de la campaña de vacunación la letalidad de la enfermedad meningocócica en general disminuyó, lo que se reflejó también en otras Comunidades Autóno$\operatorname{mas}^{28,31,38}$, hasta el $2,4 \% ; 3,6 \%$ y $3,9 \%$ durante los años 1998, 1999 y 2000 respectivamente. La letalidad también difirió según el serogrupo (2,5\% para el serogrupo B y del $6,8 \%$ para el serogrupo $\mathrm{C}$ ) en el total de los tres años postvacunales y sin que existiera diferencia significativa en el riesgo de fallecer por enfermedad meningocócica por serogrupo $\mathrm{C}$ entre vacunados y no vacunados.

La relación de la tasa de ataque de enfermedad invasora por $N$. meningitidis del serogrupo $C$ en niños/as vacunados y no vacunados, durante la campaña de vacunación masiva realizada en el último trimestre del año 1997, nos ha permitido calcular la efectividad clínica de la vacuna polisacarídica durante los tres años siguientes a su administración, en la que se alcanzó una cobertura vacunal del $85,13 \%{ }^{20}$. Para valorar la efectividad vacunal hay que tener en cuenta que en el último trimestre de 1997 se vacunó a los niños y jóvenes de 18 meses a 19 años de edad con vacuna polisacarídica. Así mismo, desde el mes de octubre del año 2000 hasta finalizado febrero de 2001 se ofertó gratuitamente la vacuna conjugada frente al meningococo serogrupo $\mathrm{C}$ a los niños de 2 meses a 6 años de edad inclusive (vacuna que seguidamente se incluyó en el Calendario de Vacunaciones Sistemáticas de la Comunidad

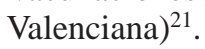

Durante el primer año tras la vacunación (1998) se valoró en un 86,2\% la efectividad clínica de la vacuna polisacarídica frente al meningococo del serogrupo $\mathrm{C}$ en el grupo de edad de 18 meses a 4 años y del 93,5\% en el grupo de edad de 5 a 14 años. Durante 1999 la efectividad de la vacuna antimeningocócica $\mathrm{A}+\mathrm{C}$ fue del $79,4 \%$ para el grupo de edad de 18 meses a 4 años y del 93,5\% para el grupo entre 5 a 14 años. En el año 2000 la efectividad de la vacuna disminuyó al 69,1\% en edades entre 18 meses a 4 años y a $83,7 \%$ en el grupo de edad de 5 a 14 años. Se observa pues una clara diferencia en la intensidad de disminución de la protección vacunal según la edad de vacunación y el tiempo transcurrido desde ella, que estaría dentro de lo esperado ${ }^{23-24,28,30-31,46,50}$. Así, con motivo de la vacunación masiva de la población de Québec entre 6 meses y 20 años de edad para controlar un brote de enfermedad por $N$. meningitidis del serogrupo $\mathrm{C}$ se observó, al finalizar el primer año tras la campaña de vacunación, una eficacia global de la vacuna polisacarídica ajustada por edad del 79\% (IC 95\%), siendo en los menores de 5 años del $70 \%$ y entre los niños de 10 a 14 años del 91\%. Dos años después de la administración de la vacuna se observó una protección global, para todas las edades, del 65\%. La eficacia vacunal sufre una disminución a partir del tercer año tras la vacunación, de modo que a los 5 años de la campaña de vacuna- 
ción la protección es casi nula ${ }^{23-24}$. La efectividad de la vacuna está en relación con la edad de vacunación, dato que concuerda con lo observado en nuestro estudio. La protección de la vacuna polisacarídica A+C durante los 18 meses tras su administración en niños brasileños de 6 meses a 3 años fue del $32 \%$ (IC 95\%) durante un brote de enfermedad meningocócica por serogrupo $\mathrm{C}$ en los años $1972-74^{50}$. La evaluación en las primeras cuatro semanas de 1997 tras la campaña de vacunación de Galicia ${ }^{46}$ encontró una efectividad vacunal del $89,6 \%$ en el grupo de 18 meses- 2 años de edad, del $97,5 \%$ en el grupo de 3-5 años y del 94,4\% en el grupo de 6-13 años. En Cantabria la efectividad de la vacuna en el primer año tras la campaña de vacunación fue del $100 \%$ (en todas las edades) y 3 años y medio después era del 88,6\%. Estos resultados mejoran los observados en nuestro estudio, hecho atribuido al haber realizado la campaña de vacunación de forma muy precoz en esta Comunidad Autónoma y haber conseguido una alta cobertura $(93,45 \%)^{30}$

Al observar la evolución de la incidencia de la enfermedad invasora por $N$. meningitidis serogrupo $\mathrm{C}$ en cada grupo de edad durante el periodo 1996-2000 (tabla 1), se aprecia que el mayor impacto vacunal se produjo en el grupo etario de 10 a 14 años inclusive manteniéndose durante los dos años posteriores y disminuyendo moderadamente al tercer año (2000), posiblemente debido a la mayor reactividad inmunógena de este grupo de edad, seguido de los niños con edades comprendidas entre 5 y 9 años (niños vacunados con vacuna polisacarídica entre los 2-6 años de edad) y de los niños de 19 meses a 4 años (casi todos son niños no vacunados). A la vista de estos resultados y según otros trabajos publicados, la vacuna polisacarídica se presenta sólo eficaz para la prevención de nuevos casos en brotes ${ }^{30,42,51}$. Por ello, estas cohortes de población infantil son las que presentan actualmente una menor protección a la enfermedad invasora por N. meningitidis del serogrupo C.
La reducción de casos en menores de 18 meses en los años 1998 y 1999 no influidos por la campaña de vacunación de 1997, circunstancia reflejada también en otro estudio $^{28}$, resulta difícil de explicar a menos que se recurra al efecto de la inmunidad de grupo y a la reducción de la circulación del microorganismo en la población general; hay que recordar, sin embargo, que no se ha demostrado tal eventualidad ${ }^{23-24,40}$. El llamativo descenso de la incidencia en niños/as de 1 mes a 18 meses en el año 2000 (tasa: 1,87) respecto al año anterior (tasa: 5,61 ) a diferencia de los otros grupos etarios, la consideramos atribuible a la vacunación con vacuna conjugada antimeningocócica $\mathrm{C}$ en el último trimestre del año 2000, lo que nos estaría provocando un solapamiento de la efectividad de ambas vacunas. De ser cierta la interpretación propuesta deberíamos haber esperado que la morbilidad en los grupos etarios mayores de 18 meses hubiera sido mucho mayor si no se hubiese realizado la última campaña de vacunación con vacuna conjugada.

La vacuna meningocócica conjugada para el serogrupo C podría subsanar las limitaciones de la vacuna de polisacáridos ${ }^{32,43,51-53}$ e incluso, como sucede con las vacuna conjugadas del $H$. influenza tipo b, se podría reducir la frecuencia de portadores nasofaríngeos en los vacunados disminuyendo la tasa de transmisión y provocando una inmunidad de grupo ${ }^{24,54-56}$. Dada la situación endémica de la enfermedad meningocócica producida por el serogrupo $\mathrm{C}$ y las características inmunológicas de la nueva vacuna conjugada, creemos conveniente mejorar la protección de las cohortes de población infantil actualmente más desprotegidas a la enfermedad invasora por $N$. meningitidis del serogrupo C, principalmente las cohortes de 19 meses a 4 años y de 5 a 9 años para conseguir, posiblemente, en éstas una completa inmunización con la vacuna conjugada. Igualmente, consideramos de gran interés continuar, durante al menos dos años, con el seguimiento de la evolución epidemiológica de la 
enfermedad meningocócica para poder valorar el impacto sobre la salud infantil de la medida adoptada y planificar en consecuencia las acciones posteriores más pertinentes.

\section{AGRADECIMIENTOS}

La realización de este estudio ha sido posible gracias a la dedicación y el esfuerzo realizado por el personal facultativo de los Servicios de Pediatría de los hospitales públicos de la Comunidad Valenciana y el apoyo de la Dirección General para la Salud Pública.

\section{BIBLIOGRAFÍA}

1. World Health Organization. Vaccins antiméningococciques groupes A et C. Wkly Epidemiol Rec 1999; 74:297-304.

2. Comité Asesor de Vacunas (CAV) de la Asociación Española de Pediatría (AEP). Manual de Vacunas en Pediatría. $2^{\text {a }}$ Edición. Madrid: Asociación Española de Pediatría; 2001.

3. Centers for Disease Control and Prevention (CDC). Prevention and control of meningococcal disease : Recommendations of the Advisory Committee on Immunization Practices (ACIP). MMWR 2000; 46/No.(RR-7):1-10.

4. American Academy of Pediatrics. Committee of Infections Disease. Meningococcal disease prevention and control strategies for practice-based physicians. Pediatrics 1996; 97: 404-412.

5. Jackson LA, Schuchat A, Reeves MW, Wenger JD. Serogroup C meningococcal outbreaks in the United States. JAMA 1995; 273: 383-9.

6. Harrison LH. The world-wide prevention of meningococcal infection: still an elusive goal (editorial). JAMA 1995; 273: 419-21.

7. Vázquez JA. Infección meningocócica. Información del laboratorio de referencia de meningococos. Años 1989-1992. Bol Epidemiol Microbiol1993; (11): 209-11.

8. Miguel C. Infección meningocócica. Información procedente del Sistema de Enfermedades de Declaración Obligatoria y Sistema de Información
Microbiológica. Bol Epidemiol Microbiol 1993; 1 (11): 212-4

9. Burgoa M, Asensio O, García C, Rotaeche V, Mateo S. Vigilancia de la enfermedad meningocócica. Bol Epidemiol Sem 1996; 4: 97-100.

10. Mateo S. Enfermedad meningocócica en España Temporada 1995-1996. Bol Epidemiol Sem 1996; 4: $205-12$.

11. Traducción del Boletín Epidemiológico de Galicia, 1996 IX (4). La enfermedad meningocócica en Galicia: temporada 1995-96. Bol Epidemiol Galicia 1996; 9: 1-4.

12. Instituto Carlos III. Centro Nacional de Epidemiología. Vigilancia epidemiológica de la enfermedad meningocócica en España. Año 1997. Boletín Epidemiológico Semanal 1997.5: 257-264.

13. Vázquez JA de la Fuente L, Berrón S. Infección meningocócica, información del laboratorio de referencia de meningococos (1995). Bol Epidemiol Semanal 1996; 4: 37-40.

14. Mateo S, Cano R, García C. Changing epidemiology of meningococcal disease in Spain. 19891997. Euro Surveill 1997; 2: 71-74.

15. Diario Oficial de la Generalitat Valenciana. Orden de 4 de marzo de 1997, de la Consellería de Sanidad, por la que se desarrolla el Sistema Básico de la Red Valenciana de Vigilancia en Salud Pública. DOGV núm 2.983, 2/5/1997.

16. Consellería de Sanitat. Conceptos básicas para la prevención y control de la infección meningocócica. Valencia: Consellería de Sanitat; 1997. Monografía Sanitaria. Serie E, núm 23.

17. Consellería de Sanitat. Vacuna conjugada contra el Meningococo del Serogrupo C. Valencia: Consellería de Sanitat; 2000. Monografía Sanitaria. Serie E, núm 32.

18. Centers for Disease Control and Prevention (CDC). Control and prevention of meningococcal disease : Recommendations of the Advisory Committee on Immunization Practices (ACIP). MMWR 1997; 46/No. (RR-5):1-10.

19. Centers for Disease Control and Prevention. Control and prevention of meningococcal disease and control and prevention of serogroup $\mathrm{C}$ meningococcal disease: evaluation and management of suspected outbreaks: Recommendations of the Advisory Committee on Inmunization Practices (ACIP). MMWR 1997; 46/No. (RR-5): 13-21. 
20. Consellería de Sanitat. Plan de prevención integral de la meningitis en la Comunidad Valenciana. Valencia: Consellería de Sanitat; 1999.

21. Diario Oficial de la Generalitat Valenciana. Orden de 11 de enero de 2001, de la Consellería de Sanidad, por la que se aprueba el nuevo calendario de vacunaciones sistemáticas infantiles en la Comunidad Valenciana. DOGV núm 3930, 01/02/2001.

22. Department of Health and the Health Education Authority. Meningococcal C (Meningitis C) Vaccine Factsheet. October 1999.

23. De Wals P, Dionne M, Douville-Fradet M, Boulianne N, Drapeau J, De Serres G. Impact of a mass immunization campaign against serogroup $\mathrm{C}$ meningococcus in the Province of Quebec, Canada. Bull World Health Organ 1996; 74: 407-11.

24. De Wals P, De Serres G, Niyonsenga T. Effectiveness of a mass immunization campaign against serogroup C menigococcal disease in Quebec. JAMA 2001; 285: 177-81.

25. MacLennan JM, Shackley F, Heath PT, Deeks JJ, et al. Safety, immunogenicity, and induction of immunologic memory by a serogroup $\mathrm{C}$ meningococcal conjugate vaccina in infants. JAMA 2000; 21: $2795-2801$.

26. Perkins BA. New opportunities for prevention meningococcal disease. JAMA 2000; 21: 28302835 .

27. Orestein W, Bernier R, Sondero T, Hinman A Mark J, Bart K et al. Field evaluation of vaccine efficacy. Bull World Health Organ 1985; 63: 10551068

28. Cano R, García C, De Mateo S. Enfermedad meningocócica. Situación en España en la temporada 1998-1999.Rev Esp Salud Pública 2000; 74: 369-75.

29. Bueno M, Baselga $\mathrm{C}$ et al (Comité de Expertos de la Asociación Española de pediatría). Meningitis bacteriana en la infancia. Situación actual en España. Epidemiología y prevención. Madrid: Gabinete de estudios Bernard Krief; 1994.

30. González de Aledo A, García J. Evaluación de la campaña de vacunación en Cantabria dos años de evolución epidemiológica. Rev Esp Salud Pública 2000; 74: 405-11.

31. Gutiérrez $\mathrm{M}^{\mathrm{a}} \mathrm{A}$, Ramírez R, García J, Moreno A Hernando M, Arce A, Sendra JM, Bueno R. Evolución de la enfermedad meningocócica en la Comu- nidad de Madrid. Efectividad de la vacunación antimeningocócica A+C. Rev Esp Salud Pública 2000; 74: 397-403.

32. Soult JA, Muñoz M, Lopez JD. Meningococcal disease: new prevention strategies. An Esp Pediatr 2001; 54: 65-8.

33. Jones D. Epidemiology of meningococcal disease in Europe and the USA. En: Meningococcal Disease. Cartwright K (ED). Chichester: John Wiley and Son; 1997.p. 147-57.

34. Brines J, Asensi F, Hernández R, Codoñer P, Otero C, Perez A and Grupo Colaborativo del Estudio de la Meningitis en la CV. Etiology of bacterial meningitis in Valencia. The 16th Annual Meeting of the ESPID. Bled 27-29 May 1998. Abstract Book.p. 67.

35. Brines J, Diez J, Morant A. Introducción a la epidemiología de las enfermedades invasoras en la Comunidad Valenciana y su reflexión vacunal. Bol Soc Val Pediatr 1998; 18: 157-65.

36. Morant A, Díez J, Gimeno C, de la Mula N, Pereiro I, Brines J. Epidemiología de la meningitis producida por Haemophilus influenzae tipo b, Neisseria meningitidis y Streptococcus pneumoniae en niños de la Comunidad valenciana, España. Rev Neurol 1998; 26 (149): 34-37.

37. Instituto Carlos III. Centro Nacional de Epidemiología. Bacteriemias. Casos notificados al sistema de información microbiológica. Años 1995, 1996 y 1997. Boletín Epidemiológico Semanal 1998. 6: 85-92.

38. Boletín Epidemiológico de la Región de Murcia. Estudio de anticuerpos frente a N. meningitidis serogrupo C tras la campaña de vacunación en la Región de Murcia. 1999. Vol 20. núm 603, diciembre 1999 .

39. Mitchell LA, Ochnio JJ, Glover C, Lee AJ, Ho Mk, Bell A. Analysis of meningococcal serogroup Cspecific antibody levels I British Columbian children and adolescents. J Infect Dis 1996; 173: 100913.

40. Rosenstein N, Levine O, Taylor JP, Evans D, Plikaytis BD, Wenger JD, Perkins BA. Efficacy of meningococcal vaccine and barriers to vaccination. JAMA 1998; 279 (6): 435-9.

41. Alcalá B, Vázquez J. Situación de la cepa epidémica de Neisseria meningitis C:2b:P1.2,5 después de la vacunación A+C. Rev Esp Salud Pública 2000; 74: 377-9. 
42. González JI, Sáiz C, Cortina S, Cortina P. Vacunas frente al meningococo serogrupo C. Medicina Integral 1997; 5: 222-6.

43. Kaczmarski EB. Análisis de la campaña de vacunación frente a la Neisseria meningitidis serogrupo C en el reino Unido. 1er congreso de la Asociación Española de Vacunología. Cádiz 15-17 Nov 2001. Mesa redonda. P. 193-200.

44. González de Aledo A. Sobre la recomendación de vacunación contra la meningitis C en Cantabria. An Esp Pediatr 2001; 55: 379-81.

45. Vázquez J. Enfermedad meningocócica y vacunación: Un nuevo escenario. Vacunas 2002; 1: 117 22.

46. Traducción del Boletín Epidemiológico de Galicia, 1996; X, (6). La Campaña de vacunación frente al meningococo C: Resultados y primera evaluación. Bol Epidemiol Sem 1996; 4: 393-6.

47. Domínguez A, Fernández F, Prats G. Vacuna antimeningocócica. En Salleras Sanmartí Ll. Vacunaciones preventivas. Principios y aplicaciones. Barcelona: Masson SA; 1998.

48. Steven N, Wood M. The clinical spectrum of meningococcal disease. En Meningococcal Disease. Cartwright K (ED). Chichester: John Wiley and Son; 1997.p. 177-205.

49. De Mateo S. La enfermedad meningocócica en España, 1990-1997. Cambio en su patrón epidemiológico. Rev Esp Salud Pública 2000; 74: 387 96.

50. Taunay AE, Feldman RA, Bastos CO, Galvao PAA, Morais JS, Castro IO. Avaliaçao do efeito protetor de vacina polisacarídica antimeningocócica do grupo C, em crianças de 6 a 36 meses. Rev Inst Adolfo Lutz 1978; 32: 77-82.

51. Ramsay ME, Andrews N, Kaczmarski EB, Miller E. Efficacy of meningococcal serogroup $\mathrm{C}$ conjugate vaccine in teenagers and toddlers in England. Lancet 2001; 357: 195-6.

52. Lieberman JM, Chiu SS, Wong VK, Partidge S, Chang SJ, Chiu CY et al. Safety and immunogenecity of a serogroup A/C N. meningitidis oligosaccharide-protein conjugate vaccine in young children. A randimized controlled trial. JAMA 1996; 275(19): 1499-503.

53. English M, MacLennan JM, Bowen-Morris JM, Deeks J, Boardman M, Brown K, Smith S, Buttery J, Clarke J, Quataert S, Lockhart S, Moxon ER. A randomised, double-blind, controlled trial of the immunogenicity and tolerability of a meningococcal group $\mathrm{C}$ conjugate vaccine in young British infants. Vaccine 2000; 19: 1232-8.

54. Eskola j, Käyhty H. Ten years experience with Haemophilus influenzae type b (Hib) conjugate vaccine in Finland. Rev Med Microbiol 1996; 7:231-41.

55. Perdue D, Bulkow L, Gellin B, Davidson M, et al.Invasive Haemophilus influenzae disease in Alaska residents aged 10 years and older before and after infant vaccination programs. Jama 2000; 23:3089-94.

56. Peltola H. Worldwide Haemophilus influenzae type $b$ disease at the beginning of the 21 st century: Global analysis of the disease burden 25 years after the use of the polysaccharide vaccine and a decade after the advent of conjugates. Clin Microbiol Rev 2000; 13:302-17. 